\title{
Biodegradation of Starch Blended High Density Polyethylene using Marine Bacteria Associated with Biofilm Formation and its Isolation Characterization
}

\author{
Thangavelu Muthukumar ${ }^{1,3}$, Adithan Aravinthana $^{1}$, R Dineshram ${ }^{2}$, Ramasamy Venkatesan ${ }^{2}$ and Mukesh Doble ${ }^{1 *}$ \\ ${ }^{1}$ Bioengineering and Drug Design Lab, Department of Biotechnology, Indian Institute of Technology Madras, Chennai, India \\ ${ }^{2} \mathrm{OSTI}$, National Institute of Ocean Technology, Chennai, India \\ ${ }^{3}$ Bio-products Laboratory, Central Leather Research Institute, Adyar, Chennai, India
}

\begin{abstract}
The biofouling and biodegradation of starch blended high density polyethylene (HDPE) was studied by immersing it in Bay of Bengal (India) for a period of six months. A positive correlation was observed amongst the various constituents in the biofilm. FTIR spectrum showed the formation of $\mathrm{C}-\mathrm{O}$ stretching band and decrease in ester and keto carbonyl bands indicating biodegradation. $17 \%$ weight loss was observed, while the polymer surface turned hydrophilic. Twenty two bacterial strains were isolated from the biofilm and biochemically characterized. 16sRNA sequence analysis was performed for three strains. In vitro biodegradation of the polymer exposed to sunlight for 150 days incubated with the isolated pure strain (Exiguobacterium) and combination of two strains (Exiguobacterium and B. subtilis) for 75 days, showed a gravimetric weight loss of 4.7 and $12.1 \%$ respectively indicating synergy between the two organisms. The current study indicated, the isolated microorganisms could degrade starch blended HDPE.
\end{abstract}

Keywords: Biodegradation; Biofilm, Starch blended HDPE, Bacillus subtilis; Exiguobacterium sp., ATP

\section{Introduction}

High density polyethylene (HDPE), particularly as a thin film, is widely used in food, clothing, shelter, transportation, construction, medical, and recreation industries. Its disposal after use causes several environmental issues because of its recalcitrant nature. The rate of biodegradation of this polymer dumped in the open environment is very slow due to the strong intermolecular bond that does not allow the microbes to access them easily. This polymer accumulates at a rate of 25 million ton per year in the terrestrial and in the marine environment [1]. Also the dumping of the waste material in the sea is the causative agent of major marine pollution. It has been estimated that more than a million of marine animals are being killed every year either by choking on floating plastic items or by becoming entangled in plastic debris. Fishing and shipping industries are a major cause of plastic litter. The two major problems which hinder the biodegradation of polypropylene are its high hydrophobicity and molecular weight. The only way to solve this problem is to develop biodegradable polymers [2]. Many conventional techniques are adopted to dispose plastics which include incineration, pyrolysis, landfill, and recycling which involves many technical and economical problems. Synthetic plastics mixed with natural polymers including starch or alginate degrades when dumped in open environment. This degradation leads to changes in their physical and mechanical properties. This degradation can be enhanced by mild physico-chemical pretreatment including thermal or UV treatment [3]. The biodegradability of high density polyethylene has been enhanced by introducing additives to it, including starch and pro-oxidants $[4,5]$.

Ocean contains a large number of micro and macro-organisms, which could involve in the degradation of the polymer. Attachment of microorganisms to form a biofilm on the surface of the polymer is the first step in the process of biodegradation. It begins with the reversible attachment followed by an irreversible adhesion of microorganisms to the substratum [6]. The initially attached cells can be easily removed by a gentle wash since it is held by physical forces whereas the later attachment is mediated by hydrogen bonding, cation bridging, and receptor ligand interaction [7]. During the biofilm formation on the surface bacteria overproduces extracellular polymeric substances (EPS) [8]. EPS build up the biofilm matrix, serving as a multipurpose functional element for adhesion, protection, immobilization of cells and facilitating spatial arrangement of different species [9]. Rhodococcus ruber and B. borstelensis [10], have been reported to colonise polyethylene by forming biofilm and later degrade it. Only $0.75 \%$ weight loss was observed when pure HDPE was immersed in sea water for a period of six months [11].

The present study aimed to understand the biofouling and biodegradation of starch blended high density polyethylene (HDPE) immersed in sea water and isolating microbial species that can able to degrade starch blended HDPE in minimum time.

\section{Materials and Methods}

\section{Experimental materials}

Commercially available 5\% (w/w) starch blended HDPE (Bio Bags, Chennai, India) film of size $10 \times 7.5 \mathrm{~cm}$ and $0.23 \mathrm{~mm}$ thickness was used in this present study. The samples were washed with $70 \%$ ethanol, followed by distilled water and dried in a hot air oven for $5 \mathrm{~h}$ at $40^{\circ} \mathrm{C}$. Later the samples were brought to room temperature and kept for

*Corresponding author: Mukesh Doble, Bioengineering and Drug Design Lab, Department of Biotechnology, Indian Institute of Technology Madras, Chennai, Tamilnadu 600036, India, Tel: +91 442257 4107; Fax: +91 44 22574102; E-mail: mukeshd@iitm.ac.in

Received February 14, 2014; Accepted February 26, 2014; Published March 03 2014

Citation: Muthukumar T, Aravinthana A, Dineshram R, Venkatesan R, Doble M (2014) Biodegradation of Starch Blended High Density Polyethylene using Marine Bacteria Associated with Biofilm Formation and its Isolation Characterization. J Microb Biochem Technol 6: 116-122. doi:10.4172/1948-5948.1000131

Copyright: ( 2014 Muthukumar T, et al. This is an open-access article distributed under the terms of the Creative Commons Attribution License, which permits unrestricted use, distribution, and reproduction in any medium, provided the original author and source are credited 
Citation: Muthukumar T, Aravinthana A, Dineshram R, Venkatesan R, Doble M (2014) Biodegradation of Starch Blended High Density Polyethylene using Marine Bacteria Associated with Biofilm Formation and its Isolation Characterization. J Microb Biochem Technol 6: 116-122. doi:10.4172/1948-5948.1000131

$24 \mathrm{~h}$ before deployment in the ocean. Firefly extract was used for the estimation of adenosine triphosphate (ATP) (Sigma Aldrich, India). All the other chemicals were purchased from Himedia, India.

\section{Deployment of the polymer}

The films were immersed in the surface waters of Bay of Bengal at Ennore Port Limited (EPL) Chennai, India (Latitude $13^{\circ} 15^{\prime} 48^{\prime \prime}$ $\mathrm{N}$, Longitude $80^{\circ} 20^{\prime} 28^{\prime \prime} \mathrm{E}$ ) at a depth of $1 \mathrm{~m}$. The coupons were tied vertically to a floating raft made of high density polyethylene. This study was conducted for six months. The polymer films in triplicate were retrieved after every two months interval up to 6 months.

\section{Seawater parameters}

During the sampling period, temperature, salinity and dissolved oxygen of the sea water were measured using a pre-calibrated water quality monitoring system (Hydrolab, Quanta Instruments, USA).

\section{Biological parameters}

The films were retrieved from the sampling location and immersed in a bottle containing $500 \mathrm{ml}$ of filtered $(0.22 \mu \mathrm{m}$, Millipore $)$ and sterilized seawater. The attached biofilm (attached biomass) on the polymer film was scraped using a sterile nylon brush into the container containing filtered sterilized water [12]. The sample in the container was mixed thoroughly. Then this $1 \mathrm{ml}$ of sample was transferred to an Eppendorf tube and was serially diluted prior to further experiments. It was also plated on Zobell Marine Agar as well as on Pseudomonas agar (Himedia, India). After $24 \mathrm{~h}$ of incubation at $28 \pm 2^{\circ} \mathrm{C}$ [13], Total viable count (TVC) were counted manually.

The total suspended solids (TSS), total carbohydrate, total protein, chlorophyll a, adenosine triphosphate (ATP), Pseudomonas and total viable count in the biofilm formed on the polymer were measured once every two months. The above parameters play a vital role in determining the extent of biofouling on a substrate. The total suspended solids in the biofilm were estimated based on the method reported by Parson et al [14]. A sample of $10 \mathrm{ml}$ was filtered through a pre-weighed (Sartorius CP64, $0.1 \mathrm{mg}$ accuracy) GF/C filter ( $47 \mathrm{~mm}, 1.25 \mu \mathrm{m}$, Whatman), dried at $100^{\circ} \mathrm{C}$ for $1 \mathrm{~h}$ and reweighed to get the dry weight of the residual biomass. The total carbohydrate and protein content in the biofilm were estimated using phenol - sulphuric acid method [15,16], and Lowry's method [17] respectively.

Chlorophyll a content ( $\mathrm{chl}$ a) indicates the amount of algal biomass present on the polymer coupons. The filtrate with the filter paper was placed in a screw capped centrifuge tube containing $10 \mathrm{ml}$ of $90 \%$ acetone and was stored at $-20^{\circ} \mathrm{C}$ until further analysis [18]. The chlorophyll a pigment was measured with a spectrophotometer (Perkin Elmer, Lambda 35, USA). For estimation of ATP, the filter paper was kept in $3 \mathrm{ml}$ of $0.02 \mathrm{M}$ Tris ( $\mathrm{pH}$ 7.5) buffer and boiled for $10 \mathrm{~min}$ and stored at $-20^{\circ} \mathrm{C}$ until the analysis was carried out using the method reported by Hamilton et al [19]. All the measurements were performed in triplicates. Correlation coefficients between various parameters were determined using SPSS software Version 15.0.

\section{Isolation and identification of bacteria from biofilm}

Twenty two bacterial colonies were isolated and they were named serially from NRBMD 1 to NRBMD 22 and their morphological, biochemical and molecular characteristics were determined. The bacteria with distinct morphology and which showed positive results on the starch utilization test were purified and sub cultured using respective agar medium. From this group three bacterial isolates were selected and were maintained at $4^{\circ} \mathrm{C}$ for further characterization studies. The morphologies of these organisms were also observed by growing them for $24 \mathrm{~h}$ at room temperature in nutrient agar medium.

These three strains were identified based on their $16 \mathrm{~S}$ rDNA sequence. The genomic DNA from these bacteria was extracted using phenol chloroform method after incubating them in Zobell Marine Broth for $24 \mathrm{~h}$ [20]. PCR amplification of almost the full length of the $16 \mathrm{~S}$ rDNA was performed with the template DNA using the universal forward and reverse primers 5'GAGTTTGATCCTGGCTCA3' and 5'ACGGCTAACTTGTTACGACT3' respectively [21]. The conditions used were as follows, The initial incubation was performed at $95^{\circ} \mathrm{C}$ for 5 min, later denaturation at $94^{\circ} \mathrm{C}$ for $1 \mathrm{~min}$, annealing at $55^{\circ} \mathrm{C}$ for $1 \mathrm{~min}$, extension at $72^{\circ} \mathrm{C}$ for $2 \mathrm{~min}$. The same conditions were repeated for 30 cycles and finally a 7 min extension at $72^{\circ} \mathrm{C}$ [21]. The PCR product was confirmed by $1 \%$ agarose gel and it was sent for sequencing to an external agency (Anshul Biotechnologies, Hyderabad, India).

\section{EPS producing ability}

Bacterial strains were grown in Zobell Marine Agar (Himedia, India) and then they were transferred to test tubes containing Zobell Marine Broth and incubated for $24 \mathrm{~h}$ at $28 \pm 2^{\circ} \mathrm{C}$. A day prior to the experiments, $200 \mu \mathrm{l}$ of the inoculum was transferred from the broth aseptically to a $250 \mathrm{ml}$ conical flask containing $50 \mathrm{ml}$ of modified basal salt solution [22]. The culture broth was inoculated and incubated at $28 \pm 2^{\circ} \mathrm{C}$ for $5 \mathrm{~d}$ at $180 \mathrm{rpm}$. The bacterial cells were removed from the culture broth by centrifugation at $10,000^{\star} \mathrm{g}$ for $20 \mathrm{~min}$ [7]. The supernatant was mixed with 3 volumes of ethanol and kept at $4^{\circ} \mathrm{C}$ for $24 \mathrm{~h}$. Then it was centrifuged $\left(10,000^{*} \mathrm{~g}, 4^{\circ} \mathrm{C}, 20 \mathrm{~min}\right)$, the EPS was precipitated and maintained at $80^{\circ} \mathrm{C}$ for 3 days. The amount of EPS produced by each strain was measured using the method suggested by Kwon et al [23]. The procedure makes use of phenol sulphuric acid $[15,24]$. Briefly, $2 \mathrm{ml}$ of the culture broth was centrifuged and filtered through $0.22 \mu \mathrm{m}$ (Millipore) filter, transferred to a dialysis bag and was dialyzed against distilled water for $48 \mathrm{~h}$ at $4^{\circ} \mathrm{C}$. After the dialysis, the samples were made up to a volume of $3 \mathrm{ml}$. From this, $500 \mu \mathrm{l}$ of the content was taken for the estimation of EPS, using glucose as the standard and the absorbance was read at $490 \mathrm{~nm}$.

\section{Bacterial adhesion to hydrocarbon (BATH)}

BATH assay was performed to determine the hydrophobicity of the surface of the isolated bacterial cultures [24]. All the organisms were inoculated in a modified basal salt solution and incubated at $26 \pm 2^{\circ} \mathrm{C}$ for $18 \mathrm{~h}$ to get mid $\log$ phase culture. They were centrifuged and washed with phosphate buffered saline twice and the optical density of the cells was adjusted to 0.2 at $540 \mathrm{~nm}$ with the same buffer. To $3 \mathrm{ml}$ of bacterial cell suspension, $100 \mu \mathrm{l}$ of $\mathrm{n}$-hexadecane (Himedia, India) was added. Then the suspension was vortexed for $1 \mathrm{~min}$ and the two phases were allowed to separate for $15 \mathrm{~min}$. The absorbance of the aqueous phase was measured at $400 \mathrm{~nm}$ using a spectrophotometer (Perkin Elmer, Lambda 35, USA). Absorbance of the bacterial suspension without the addition of hexadecane was used as the control. The percentage of the cells bound to $n$-hexadecane was calculated using the following formula:

$\%$ of bacterial cell adhered to hexadecane $=((1-\mathrm{A})) / \mathrm{A}_{\mathrm{o}} \times 100$

Where $\mathrm{A}_{\mathrm{o}}$ and $\mathrm{A}$ are the absorbance at $400 \mathrm{~nm}$ of the bacterial suspension without and with $\mathrm{n}$-hexadecane respectively. 
Citation: Muthukumar T, Aravinthana A, Dineshram R, Venkatesan R, Doble M (2014) Biodegradation of Starch Blended High Density Polyethylene using Marine Bacteria Associated with Biofilm Formation and its Isolation Characterization. J Microb Biochem Technol 6: 116-122. doi:10.4172/1948-5948.1000131

\section{Physicochemical properties of the polymer}

Hydrophobicity of the polymer surface is determined by measuring its contact angle using sessile drop method with easy drop contact angle measuring Goniometer (Kruss, Germany). Millipore grade distilled water is used as the wetting liquid. An average of five measurements is reported here $[25,26]$. Contact angle is directly proportional to the hydrophobicity of the surface.

Gravimetric weight loss is a simple and quick way to determine the degradation of the polymer. The macrofoulants from the polymer surface are removed by immersing the scraped films in $10 \%$ hydrochloric acid for few minutes, then washing them with distilled water and later drying them in a hot air oven at $40^{\circ} \mathrm{C}$ for $4 \mathrm{~h}$ [27]. Samples are weighed with an accurate four digit balance (Sartorius CP64, $0.1 \mathrm{mg}$ accuracy).

Scanning Electron Microscopy (SEM) and Energy Dispersive Analysis of X-rays (EDAX) of the HDPE samples retrieved from the site were performed to detect the changes on the surface morphology and elemental composition due to degradation respectively with a JEOL JSM-6500F, (Tokyo, Japan). The latter was performed at an acceleration voltage of $10 \mathrm{kV}$ resulting in a lateral and depth compositional resolution of approximately $5 \mu \mathrm{m}$.

Chemical changes which might have occurred in the polymer due to deployment were measured using Fourier transform infrared (FTIR) Jasco N4200 (Japan) Spectrometer. The spectra were recorded as an average of 32 scans at a resolution of $4 \mathrm{~cm}-1$ in the frequency range of $4000-500 \mathrm{~cm}^{-1}$. The $\mathrm{C}-\mathrm{O}$ peak, $\mathrm{CH}_{2}$ deformation, $\mathrm{CH}_{2}$ bending (symmetrical), $\mathrm{CH}_{2}$ bending (asymmetrical) and $\mathrm{CH}_{2}$ stretching were compared with the control sample as a reference. The control samples were those which were kept in the laboratory at room temperature for the same study period. The keto carbonyl, ester carbonyl, and vinyl indices for the polymer were calculated using the following formula with respect to the intensity of methylene group.

Keto carbonyl bond index $=$ I1715/ I1465

Ester carbonyl bond index $=$ I1740/I1465

Vinyl bond index $=\mathrm{I} 1640 / \mathrm{I} 1465$

Where relative intensities at $1740,1715,1640$ and $1465 \mathrm{~cm}^{-1}$ correspond to ester and keto carbonyls, double bond (vinyl index) and methylene band respectively [28].

Thermograms of the polymer samples were recorded using a Differential Scanning Calorimeter (DSC) and Thermo Gravimetric/ Differential Thermal Analyzer (TG/DTA) (Model 204, Netzsch, Germany). Scans were performed under nitrogen atmosphere in the temperature range of -50 to $450^{\circ} \mathrm{C}$ and -28 to $600^{\circ} \mathrm{C}$ respectively, at a heating rate of $10^{\circ} \mathrm{C} / \mathrm{min}$. The melting temperature $(\mathrm{Tm})$ and percentage crystallinity were calculated from the thermograms [29]. The enthalpy of $100 \%$ crystalline $\operatorname{HDPE}\left(\Delta \mathrm{H}^{\circ} \mathrm{m}\right)$ is $288 \mathrm{~J} / \mathrm{g}$ and is taken as a reference [30].

$$
\% \text { Crystallinity }=100 \times \Delta \mathrm{H} \mathrm{m} / \Delta \mathrm{H}^{\circ} \mathrm{m}
$$

\section{In vitro biodegradation studies}

The samples were exposed to sunlight for 150 days and their biodegradation were monitored in vitro for 75 days with the three bacteria isolated from the biofilm obtained during the first part of our study formed on the polymers when they were deployed in sea. Samples unexposed to sunlight were also subjected to similar biodegradation with the bacterial isolates. Pretreated films $(80 \mathrm{~mm} \times 25 \mathrm{~mm})$ were taken in conical flask and $100 \mathrm{ml}$ aliquots of filtered $(0.22 \mu \mathrm{m}$ Millipore filter paper) and autoclaved seawater was added to each of them. Log phase seed culture ( $1 \%$ of overnight grown culture containing 107 cells) was added to these flasks and they were kept under shaking at $180 \mathrm{rpm}$ at $35-37^{\circ} \mathrm{C}$ (Scigenics Biotech, Chennai, India). Sea water containing polymer without the microorganism was maintained as positive control and organism without the polymer served as a negative control $[2,31]$.

\section{Viability of the bacterial biofilm}

Viability of the bacterial biofilm (live and dead cells) present on the polymer sample was determined by using Live/Dead $\mathrm{Bac}$ Light $^{\mathrm{TM}}$ Bacterial viability Kit (Invitrogen, Germany), according to the manufacturer's Instructions. The kit has two dyes SYTO9 (green colour) stains the live cells and propidium iodide (red colour) stains only the dead cells. The polymers were removed at the end of in vitro study from the conical flask and were stained with Bac light, incubated for 10-15 $\mathrm{min}$ in the dark and then the images were captured with a blue filter at an excitation of $475 \mathrm{~nm}$ under a fluorescence microscope (Leica DM5000, Germany).

\section{Statistical analysis}

Results are reported as mean \pm S.D $(n=3)$. Pearson correlation coefficient between various parameters was estimated using SPSS software Version 15.0. The observed differences were considered statistically significant when $\mathrm{p}<0.05$.

\section{Results and Discussions}

\section{Biological characterization of biofilms and total suspended solids (TSS)}

The average temperature, $\mathrm{pH}$, salinity and dissolved oxygen over the six month study period of the sea water at Ennore port were $28 \pm$ $1{ }^{\circ} \mathrm{C}, 8.18 \pm 0.06,33.67 \pm 2(\mathrm{ppt})$ and $4.57 \pm 0.31(\mathrm{mg} / \mathrm{l})$ respectively. The extent of biofouling on the starch blended HDPE polymer deployed for a period of six months is seen in photographs (Figure 1a-1c). The images were taken as soon as the films were retrieved from the ocean.

Season influences the accumulation of total suspended solids and macrofoulants on the polymer surface (Figure 2a and 2b). Maximum fouling load is observed during the month of September, which is manifested in large values in all the measured biomass parameters (TSS, protein, carbohydrate, chlorophyll a, and ATP). It reduced in the
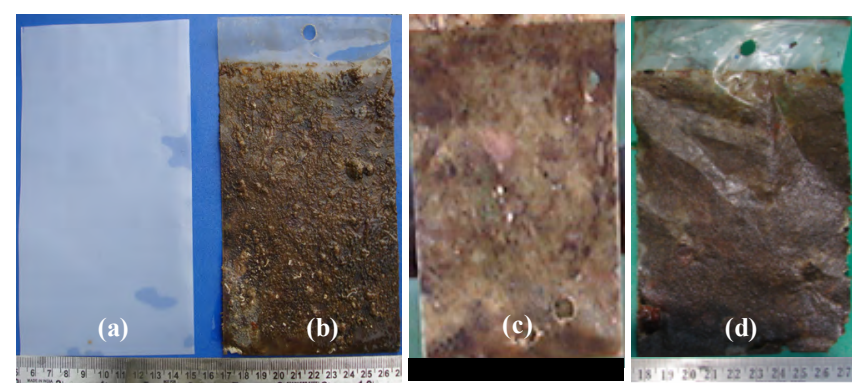

Figure 1: Fouling of starch blended HDPE in marine environment (a) contro (unimmersed) and immersed after two months (b), four months (c), and six months (d). 
Citation: Muthukumar T, Aravinthana A, Dineshram R, Venkatesan R, Doble M (2014) Biodegradation of Starch Blended High Density Polyethylene using Marine Bacteria Associated with Biofilm Formation and its Isolation Characterization. J Microb Biochem Technol 6: 116-122. doi:10.4172/1948-5948.1000131

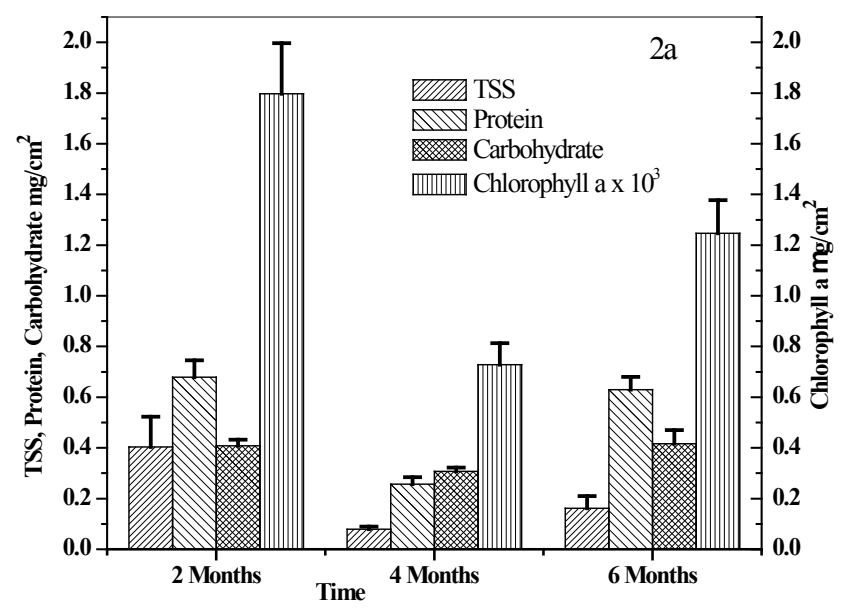

Figure 2a: Characteristic of biofilm parameters on starch blended HDPE as a function of time.

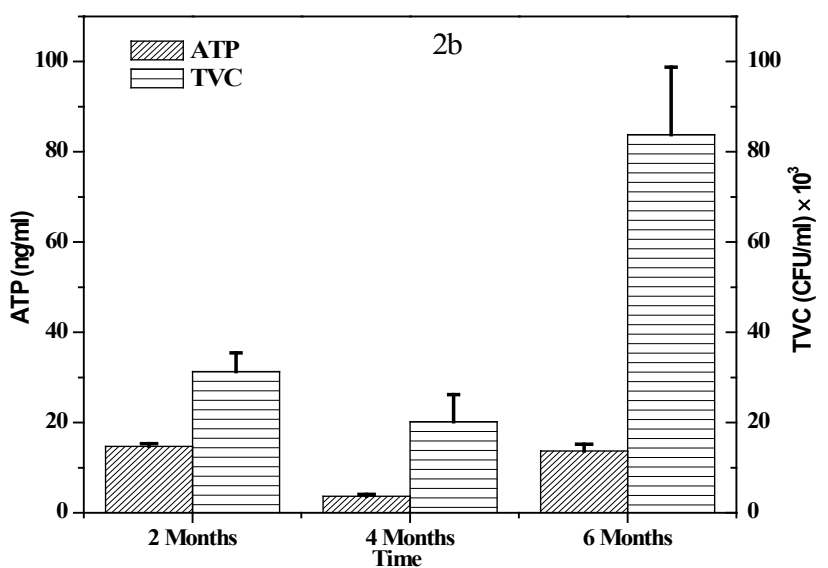

Figure 2b: ATP and TVC in the biofilm on starch blended HDPE as a function of time.

month of November and again it increased during January. Biofilm is made up of total suspended solids whose accumulation is dependent on the season [32]. The TVC and pseudomonas count were high during the month of September (Southwest-Northeast monsoon transition), and it later decreased in November. The termination of South West monsoon and commencement of North East winds leads to changes in ocean currents and influx of heavy silt-laden freshwater in October. The North East monsoon lasts from October to December and these observations have been supported by earlier reports [11,27]. Another reason for the observed variation in the biofouling load between the months could be due to continuous fouling and dislodgment of biomass from the surface [27].

There is a strong positive correlation between the various biomass and biofouling parameters (Table 1). ATP is a measure of the amount of viable microfoulants present on the polymer. It shows a strong positive correlation $(\mathrm{p}<0.01)$ with pseudomonas count $(\mathrm{r}=0.89)$, protein $(\mathrm{r}=$ $0.88)$ and carbohydrate $(r=0.95)$. However this is to be expected since all these parameters are the direct measure of the biofouling, hence a positive correlation is observed amongst each other.

\section{Identification of biofilm forming bacteria}

In the present study, the biofilm samples were collected from the HDPE starch blended polymer and were plated on pseudomonas and Zobell marine agar media. The morphological, biochemical and molecular characteristics of a total of three abundantly found isolates were investigated. The staining report showed that all the three isolated strains were Gram positive, and found to hydrolyze starch (starch utilization test) as well as catalase positive. Whereas they showed negative results for indole, methyl red, and citrate utilization tests.

The three abundantly found isolates had different morphology, size and growth pattern. The nucleotide sequences obtained for the three bacteria were compared with NCBI (http://www.ncbi.nlm.nih.gov/) database. The $16 \mathrm{~S}$ rDNA sequences of these microorganisms (NRBMD 14, NRBMD 16, and NRBMD 21) were determined and were deposited in GenBank, under the accession numbers, GQ357643, GQ357644 and GQ357645 respectively. NRBMD14 aggregates and forms microcolonies on the ZMA plate. NRBMD16 grows as colonies on the Nutrient Agar and appears orange in color. NRBMD21 spreads on the surface of the ZMA plate. Phylogenetic trees were constructed for all these three isolated microorganisms using the Neighbor-joining tree method using CLUSTAL W (http://align.genome.jp/) and compared with closely related species from the NCBI database (Figure $3 a$ and $3 b$ ). Their evolutionary distances are also presented in the figures. Strains NRBMD14 and NRBMD21, are closely related to Bacillus subtilis. NRBMD16 is closely related to Exiguobacterium.

NRBMD14 shares 98\% identity with other Bacillus subtilis available in the NCBI database, whereas NRBMD21 shares $99 \%$ identity with Bacillus subtilis strain ZB5. NRBMD 16 shares $87 \%$ identity with other Exiguobacterium species for query coverage of $97 \%$. It is known that Bacillus spp adapts to diverse habitats which vary widely in space and environmental conditions. Exiguobacterium is also reported to adapt to a wide range of environments with temperature ranging from -12 to

\begin{tabular}{|l|c|c|c|c|c|c|}
\hline Parameters & TSS & Protein & Carbohydrate & Chl a & ATP & PS \\
\hline TSS & 1 & $0.77^{*}$ & $0.65^{*}$ & $0.97^{*}$ & $0.76^{\star}$ & 0.37 \\
\hline Protein & & 1 & $0.99^{\star}$ & $0.91^{*}$ & $0.99^{\star}$ & $0.88^{*}$ \\
\hline Carbohydrate & & & 1 & $0.82^{\star}$ & $0.99^{\star}$ & $0.95^{\star}$ \\
\hline Chl a & & & & 1 & $0.9^{\star}$ & - \\
\hline ATP & & & & & 1 & $0.89^{\star}$ \\
\hline PS & & & & & & 1 \\
\hline
\end{tabular}

Table 1: Correlation coefficient between various microfouling products on HDPE immersed for 6 month at Ennore port limited (TSS-Total Suspended Solids, Chl a- Chlorophyll a, ATP - AdenosineTriphosphate and PS - Pseudomonas). ${ }^{*}$ Correlation is significant at $p \leq 0.01$ level (2-tailed).

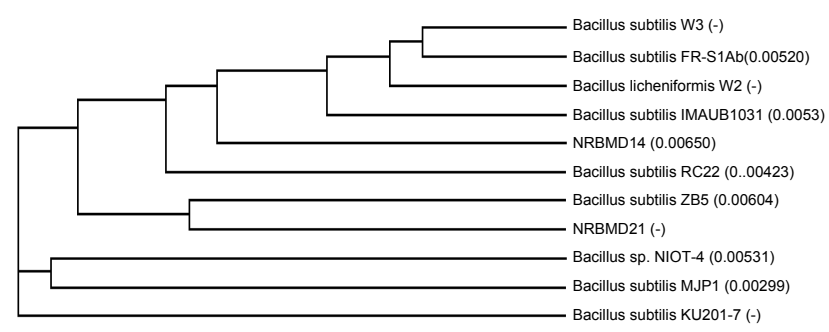

Figure 3a: Phylogenetic tree of isolated strains (NRBMD14 and NRBMD 21) showing the relationship with other Bacillus $s p$ based on 16s rRNA gene sequence constructed with neighbor joining method. 
Citation: Muthukumar T, Aravinthana A, Dineshram R, Venkatesan R, Doble M (2014) Biodegradation of Starch Blended High Density Polyethylene using Marine Bacteria Associated with Biofilm Formation and its Isolation Characterization. J Microb Biochem Technol 6: 116-122. doi:10.4172/1948-5948.1000131

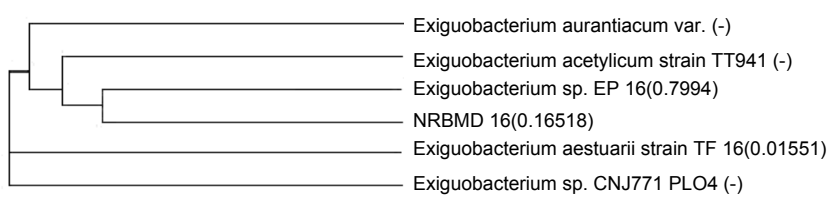

Figure 3b: Phylogenetic tree for NRBMD16 based on partial 16s rRNA gene sequence (approx.950 bp) showing the relationship of isolated specie with other Exiguobacterium species constructed using neighbor joining method.

$55^{\circ} \mathrm{C}[33]$. This could be the first report which indicates the presence of Exiguobacterium on the HDPE surface in marine environment. But it has been reported to be involved in the degradation of $\mathrm{n}$ alkanes [34].

\section{Polymer surface analysis}

The initial contact angle of HDPE starch blended polymer before deploying it in the ocean was $83 \pm 0.76^{\circ}$ and it decreased to $70 \pm 2.02^{\circ}$ at the end of six months (Table 2). This indicated that the polymer surface became relatively hydrophilic with increasing immersion period, which was also reported earlier by several authors $[13,26]$.

SEM focuses on the surface topology of the HDPE film. After 6 months in marine environment surface irregularities (Figure 4b), cracks and cavities are clearly seen when compared to the control (Figure 4a). SEM images clearly show that the surface of the polymer has been affected due to micro and macro foulants under the marine environment, leading to degradation and deterioration. The nonbiological oxidation of polyethylene is a well-known process involving radicals attacking the polymer chain, resulting in the formation of simple compounds like water, acetone, and acetic and formic acids. Elemental composition as measured by EDAX indicates that percentage of carbon has reduced from 90 to 87.4 suggesting the microbes present in the environment have utilized the polymer as one of their carbon source [35]. The increasing percentage of oxygen from 1.45 to 4.17 indicates that the polymer has undergone oxidation. The starch in the polymer could have been consumed by the microorganisms or deteriorated and could have released degraded products leading to loss of its integrity [36]. The presence of elemental silicon in EDAX of the six months old sample must be due to the biofouling by the diatoms and ocean soil since it is not present in the original polymer sample. Calcium was also detected in both the control and 6 months immersed polymer sample which might have been incorporated as an inorganic additive to improve its mechanical properties and reduces its brittleness while casting.

\section{Weight loss}

Biofilm (including solid biomass and microorganism) and macrofoulants on the polymer surface not only change its surface property but also lead to its degradation. Formation of the biofilm on the surface of the polymer leads to loss of its integrity $[4,10]$. Biodegradation is usually initiated at the surface of the polymer by the exo enzymes produced by the bacteria and hence weight loss is proportional to the surface area. Primarily, the change in the polymer morphology is due to photodegradation and surface oxidation. This is followed by biodegradation influenced by microbes and macrofoulants. In sea water polymer degradation is influenced by several factors. $17 \%$ Weight loss was observed in starch blended HDPE after six months (Table 2). The additives, fillers, softeners, antioxidants and starch in the commercial HDPE constitute $9.5 \%$ by weight. At the end of 6 months a gravimetric weight loss of $17 \%$ was observed, so the unaccounted $8.5 \%$ weight loss can be attributed to the degradation of HDPE. Studies from our lab have reported $2.5 \%$ weight loss in unblended HDPE deployed in marine water for twelve months [27]. In vitro degradation of starch blended LDPE with a marine organism, B. cereus, showed $25 \%$ weight loss in a period of 12 months [26]. In this study a strong negative correlation was observed between weight loss and contact angle $(\mathrm{r}=$ $-0.99 ; \mathrm{p}<0.05$ ), indicating that the surface had turned hydrophilic as the polymer lost its weight. A strong positive correlation $(\mathrm{r}=0.97 ; \mathrm{p}<0.01)$ was also observed between TSS and weight loss.

\section{FTIR and DSC}

The FTIR spectra (Figure 5) of the starch blended HDPE deployed for six months shows absorption frequencies corresponding to $\mathrm{CH}$ stretching at $3369 \mathrm{~cm}^{-1}, \mathrm{CH}_{2}$ deformation at $1640 \mathrm{~cm}-1, \mathrm{CH}_{2}$ bending (asymmetrical) at $1466 \mathrm{~cm}^{-1}$ and $\mathrm{CH}_{2}$ bending (symmetrical) at 1352

\begin{tabular}{|l|c|c|}
\hline Month & Weight loss in \% & Contact angle \\
\hline Initial sample & - & $83 \pm 0.76^{\circ}$ \\
\hline After 2 months & $0.60 \pm 0.2$ & $80 \pm 0.70^{\circ}$ \\
\hline After 4 months & $6.93 \pm 2.2$ & $76 \pm 1.56^{\circ}$ \\
\hline After 6 months & $17.00 \pm 1.9$ & $70 \pm 2.02^{\circ}$ \\
\hline
\end{tabular}

Table 2: Effect of fouling on contact angle and gravimetric weight loss of starch blended HDPE immersed for a period of 6 months at Ennore port.
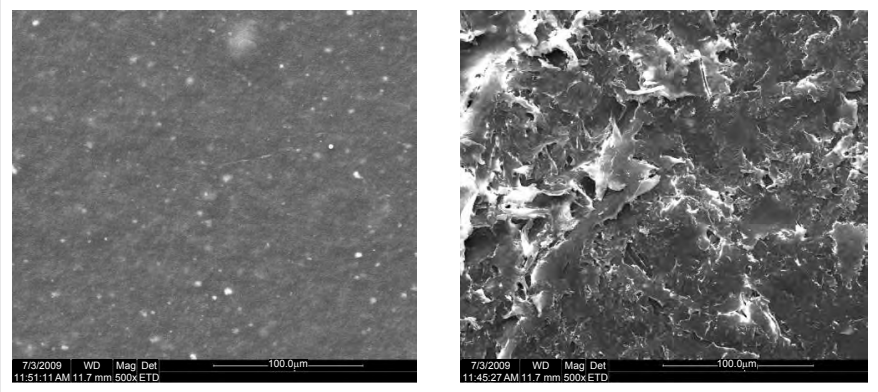

Figure 4: SEM image of starch blended HDPE (a) before and (b) after 6 months of deployment in the ocean.

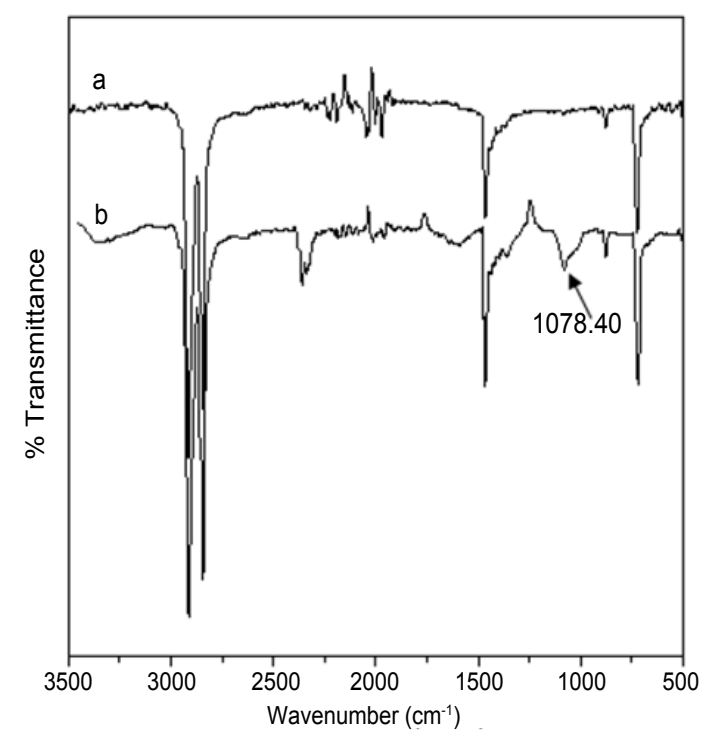

Figure 5: FTIR (Jasco N4200) spectra of starch blended HDPE (a) control (unimmersed) and (b) after 6 months of immersion. 
Citation: Muthukumar T, Aravinthana A, Dineshram R, Venkatesan R, Doble M (2014) Biodegradation of Starch Blended High Density Polyethylene using Marine Bacteria Associated with Biofilm Formation and its Isolation Characterization. J Microb Biochem Technol 6: 116-122. doi:10.4172/1948-5948.1000131

$\mathrm{cm}^{-1}$. The formation of a new C-O stretching frequency at $1078 \mathrm{~cm}^{-1}$ and a broad absorption peak at $3400 \mathrm{~cm}^{-1}$ assigned to stretching vibration of $-\mathrm{OH}$ are not seen in the control. The former band indicates incorporation of oxygen in the polymer chain. The decrease in Keto carbonyl index from $0.156 \pm 0.003$ to $0.148 \pm 0.001$, $(\mathrm{p}<0.05)$ ester index from $0.146 \pm 0.001$ to $0.128 \pm 0.002(\mathrm{p}<0.05)$ and vinyl index from 0.241 \pm 0.001 to $0.211 \pm 0.002(\mathrm{p}<0.05)$ of the 6 months old sample when compared to the original sample indicates biotic degradation. It has been reported that the decrease in the carbonyl indices with polymer which were deployed for a long period in the ocean water can be due to the formation of esters by Norrish type mechanism $[11,28]$. DSC of the control and sample retrieved from ocean after 6 months show melting peaks at 130.1 and $129.3^{\circ} \mathrm{C}$ respectively. The corresponding heats of enthalpies are 176 and $196 \mathrm{~J} / \mathrm{g}$ respectively. So it could be concluded that the \% crystallinity increased from 61.11 to 68.05 . This increase in crystallinity is possibly due to the removal of starch from the polymer or the degradation of the amorphous region in the polymer. Similar increase in crystallinity has been reported earlier [4], during invitro degradation of polypropylene.

\section{In vitro studies}

NRBMD 14, NRBMD 16 and NRBMD 21 produced $3.23 \pm 0.12$, $3.04 \pm 0.11$ and $2.75 \pm 0.13 \mathrm{mg} / \mathrm{l}$ of EPS (calculated by measuring dried EPS weight/dried cell weight) respectively indicating the amount and quality of the biofilm formed on the polymer surfaces. EPS producing ability of the bacteria is measured in terms of water soluble fraction. The amounts of EPS produced by all the three strains were found to be higher when compared with other reported strains [23]. Even though both NRBMD14 (GQ357643) and NRBMD21 (GQ357645) are the same species (Bacillus subtilis) they showed considerable differences in their EPS producing ability. The type of EPS produced is reported to be specific to certain genus or species [37]. In our study we found that higher the cell biomass higher is the EPS amount indicating that, the cell growth and the EPS produced are positively correlated with each other $(\mathrm{p}<0.01)$.

BATH test indicated that the percentages of bacteria in the $\mathrm{n}$ hexadecane phase were 3.45 (NRBMD14), 11.55 (NRBMD16) and 6.22 (NRBMD21), indicating that NRBMD16 was the most hydrophobic and NRBMD14 was the least hydrophobic amongst these three isolates. All the three strains are found to be highly hydrophilic with less than $12 \%$ absorbance in the hexadecane phase, which was isolated from starch blended HDPE, implying that hydrophilic substrate favored the attachment of hydrophilic bacteria [13]. The viable bacteria on the polymer surface after 75 days of in vitro biodegradation experiments were characterized and identified. In both the experiments more living bacterial cells (green colour) were observed on the surface of starch blended HDPE incubated with Exiguobacterium and mixture of Exiguobacterium and Bacillus subtilis (Figure S2).

Table 3 summarizes the effect of incubation of starch blended HDPE with Exiguobacterium and mixture of Exiguobacterium and Bacillus subtilis for 75 days after being exposed to sunlight for 150 days. Exposure to sunlight, leads to the formation of radicals due to the bombardment of UV radiation. Higher biodegradation is observed with UV exposed polymer than unexposed. Higher biodegradation is observed with the mixed culture $(12.1 \%)$ than with the individual culture (4.75\%), indicating possible synergy between the two organisms. The contact angle of the incubated samples decreased considerably indicating that the surface had turned relatively hydrophilic. Three bacterial strains isolated from the biofilms attached to the polymer

\begin{tabular}{|l|c|c|}
\hline Name of the polymer & Gravimetric weight loss in \% & Contact angle \\
\hline HDPE St Control & Nil & $80 \pm 0.15^{\circ}$ \\
\hline HDPE St Positive & 0.00 & $75.0 \pm 0.61^{\circ}$ \\
\hline HDPE St Exiguobacterium & 4.38 & $62.5 \pm 1.07^{\circ}$ \\
\hline HDPE St Mixed culture & 4.00 & $63.7 \pm 0.96^{\circ}$ \\
\hline HDPE UV Control & Nil & $70.3 \pm 0.08^{\circ}$ \\
\hline HDPE UV Positive & 0.00 & $63.5 \pm 0.88^{\circ}$ \\
\hline HDPE UV Exiguobacterium & 4.75 & $53.6 \pm 0.93^{\circ}$ \\
\hline HDPE UV Mixed culture & 12.08 & $50.7 \pm 1.96^{\circ}$ \\
\hline
\end{tabular}

HDPE St - Starch blended HDPE, HDPE UV - Starch blended HDPE afte aging (incubated in open sunlight for 150 days), Control- before Deployment, Positive - incubated in sea water without any Bacteria, Mixed - combination of Exiguobacterium and Bacillus subtilis

Table 3: Invitro biodegradation of starch blended HDPE after 75 days unexposed or exposed to sunlight for 150 days with marine organisms isolated from sea.

initiated degradation. In vitro studies with multiple strains is found to biodegrade the UV exposed polymer, much more than the degradation observed with the individual organism, indicating synergy.

\section{Conclusions}

Starch blended HDPE exposed to sea water for six months experienced biodegradation, significantly altering its physical and chemical properties. Starch blended polymer though cannot be a solution to tackle pollution, will invariably minimize the amount of non-degradable HDPE in the environment. In vitro studies using isolated multiple strains indicated that they could biodegrade UV exposed polymer if the right microorganism is isolated. The isolated organism are able to form a biofilm on the HDPE surface which were also found to grow on the minimal medium containing only starch blended HDPE even without nitrogen source. These organisms could be further exploited through molecular biology techniques to enhance biodegradation of such recalcitrant polymers. Hence, further studies are necessary to adequately assess the environmental decomposition of biodegradable polymers, particularly in sea water. This study is the first step in understanding the biofilm diversity and their usefulness in handling recalcitrant marine pollutants.

\section{Acknowledgement}

We thank the Naval Research Board, New Delhi, for providing us the financial support to carry out this research work. Sophisticated analytical instrument facility, IIT Madras for analytical support, and Mr. P. Kumar, Department of Metallurgy, IITM for his help during sample collection.

\section{References}

1. Orhan $Y$, Buyukgungor $H$ (2000) Enhancement of biodegradability of disposable polyethylene in controlled biological soil. Int Biodeter Biodegr 45: 49-55.

2. Doi Y, Kaneshwa Y, Tanahashi N, Kumagai Y (1992) Biodegradation of Microbial Polyesters in the Marine Environment. Polym Degrad Stabl 36: 173177.

3. Kawai F (1995) Breakdown of plastics and polymers by microorganisms. Adv Biochem Eng Biotechnol 52: 151-194.

4. Arkatkar A, Arutchelvi J, Sudhakar M, Bhaduri S, Uppara PV (2009) Approaches to enhance the biodegradation of polyolefines. Open Environ Eng J 2: 68-80.

5. Jeyakumar D, Suresh G, Mukesh D (2012) Synergistic interaction of treatment and blending on the stability of high-density polyethylene. J Appl Polym Sci 125: $2790-2798$.

6. Morisaki H1, Nagai S, Ohshima H, Ikemoto E, Kogure K (1999) The effect of motility and cell-surface polymers on bacterial attachment. Microbiology 145 : 2797-2802.

7. Jayaraman M, Seetharaman J (2003) Physiochemical analysis of the exopolysaccharides produced by a marine biofoulingbacaterium Vibrio alginolyticus. Process Biochem 38: 841-847. 
Citation: Muthukumar T, Aravinthana A, Dineshram R, Venkatesan R, Doble M (2014) Biodegradation of Starch Blended High Density Polyethylene using Marine Bacteria Associated with Biofilm Formation and its Isolation Characterization. J Microb Biochem Technol 6: 116-122. doi:10.4172/1948-5948.1000131

8. Geesey GG1, White DC (1990) Determination of bacterial growth and activity at solid-liquid interfaces. Annu Rev Microbiol 44: 579-602.

9. Allison DG1, Ruiz B, SanJose C, Jaspe A, Gilbert P (1998) Extracellular products as mediators of the formation and detachment of Pseudomonas fluorescens biofilms. FEMS Microbiol Lett 167: 179-184.

10. Orr IG1, Hadar Y, Sivan A (2004) Colonization, biofilm formation and biodegradation of polyethylene by a strain of Rhodococcusruber. Appl Microbiol Biotechnol 65: 97-104.

11. Sudhakar M, Artham T, Doble M, Kumar KS, Jahan SS, et al. (2007) Biofouling and biodegradation of polyolefins in ocean waters. Polym Degrad Stabl 92: 1743-1752.

12. Bhosle NB, Nandakumar K, Venkat K, Dhople VM, Sawant SS, et al. (1989) Biological and biochemical characterization of microfouling on aluminium panels placed in the Arabian Sea. Proc Indian Nat Sci Acad 55: 51-56.

13. Sonak S, Bhosle N (1995) Observations on Biofilm Bacteria Isolated From Aluminium Panels Immersed In Estuarine Waters. Biofouling 8: 243-254.

14. Parsons T, Maita Y, Lalli CM (1984) A Manual of Chemical and Biological Methods for Seawater Analysis. Pergamon Press. New York. pp 173.

15. Dubois M, Gilles KA, Hamilton JK, Rebers PA, Smith F (1956) Colorimetric method for determination of sugars and related substances. Anal Chem 28 : 350-356.

16. D'Souza F, Garg A, Bhosle NB (2005) Seasonal Variation in the chemica composition and carbohydrate signature compounds of biofilm. AquatMicrob Eco 41: 199-207.

17. Lowry OH, Rosebrough NJ, Farr AL, Randall RJ (1951) Protein measurement with the Folin phenol reagent. J Biol Chem 193: 265-275.

18. Holm-Hansen O, El-Sayed SZ, Franceschini GA, Cuhel JRL (1977) Primary production and the factor controlling phytoplankton growth in the Southern Ocean. Gulf, Houston. In: Llano, GA, (Ed.), Adaptations within Antarctic ecosystems 11-50.

19. Hamilton RD, Holm-Hansen O (1967) Adenosine Triphosphate Content of Marine Bacteria. Limnol. Oceanogr 12: 319-324.

20. Naik PR1, Sahoo N, Goswami D, Ayyadurai N, Sakthivel N (2008) Genetic and functional diversity among fluorescent pseudomonads isolated from the rhizosphere of banana. MicrobEcol 56: 492-504.

21. Weisburg WG1, Barns SM, Pelletier DA, Lane DJ (1991) 16S ribosomal DNA amplification for phylogenetic study. J Bacteriol 173: 697-703

22. Bhosle NB (1981) Microbial degradation of petroleum hydrocarbons. PhD Thesis, University of Bombay, India pp163.

23. Kwon KK, Lee HS, Jung SY, Yim JH, Lee JH, et al. (2002) Isolation and
Identification of Biofilm-Forming Marine Bacteria on Glass Surfaces in Dae-Ho Dike. Korea. J Microbiol 40: 260-266.

24. Jain A1, Nishad KK, Bhosle NB (2007) Effects of DNP on the cell surface properties of marine bacteria and its implication for adhesion to surfaces. Biofouling 23: 171-177.

25. Muthukumar T, Aravinthan A, Doble M (2010) Effect of environment on degradation of starch blended and Oxo biodegradable polyolefins. Polym Degrad Stabl 95: 1988-1993.

26. Sudhakar M, Doble M, Murthy PS, Venkatesan R (2008) Marine microbemediated biodegradation of low-and high density polyethylenes. Int Biodeter Biodegr 61: 203-213.

27. Artham T, Sudhakar M, Venkatesan R, Nair CM, Murty KVGK, et al. (2009) Biofouling and stability of synthetic polymers in sea water. IntBiodeterBiodegr 63: $884-890$

28. Albertsson AC, Andersson SO, Karlsson S (1987) The mechanisms of biodegradation of polyethylene. Polym Degrad Stabl 18: 73-87.

29. Khabbaz F, Albertsson AC, Karlsson S (1999) Chemical and morphological changes of environmentally degradable poly (ethylene) films exposed to thermo-oxidation. PolymDegradStabl 63: 127-138.

30. Khonakdar HA, Jafari SH, Hassler R (2007) Glass-Transition-Temperature Depression in Chemically Crosslinked Low-Density Polyethylene and HighDensity Polyethylene and Their Blends with Ethylene Vinyl Acetate Copolymer. J Appl Polymer Sci 104: 1654-1660.

31. Arkatkar A, Asha A, Juwarkar, Sumit Bhaduri, Uppara PV, et al. (2010) Growth of Pseudomonas and Bacillus biofilms on pretreated polypropylene surface. In Biodeter Biodegr 64: 530-536.

32. Anderson MJ (1995) Variations in biofilms colonizing artificial surfaces: seasonal effects and effects of grazers. J Marine BiolAssoc UK 75: 705-714.

33. Vishnivetskaya TA1, Kathariou S, Tiedje JM (2009) The Exiguobacterium genus: biodiversity and biogeography. Extremophiles 13: 541-555.

34. Mohanty G, Mukherji S (2008) Biodegradation rate of diesel range n-alkanes by bacterial cultures Exiguobacterium aurantiacum and Burkholderiacepacia. Int Biodeter Biodegr 61: 240-250.

35. Hadad D1, Geresh S, Sivan A (2005) Biodegradation of polyethylene by the thermophilic bacterium Brevibacillusborstelensis. J Appl Microbiol 98: 10931100.

36. Draenert GF1, Doeblinger M, Draenert M, Gosau M (2009) High-density polyethylene facial implants show surface oxidation in SEM and EDX examination: a pilot study. Acta Biomater 5: 1158-1162.

37. Lindberg LE1, Holmbom BR, Väisänen OM, Weber AM, Salkinoja-Salonen MS (2001) Sugar composition of biofilms produced by paper mill bacteria. Appl Microbiol Biotechnol 55: 638-643. 